\title{
SUBACUTE MYOCLONIC SPINAL NEURONITIS
}

\author{
BY
}

\section{A. M. G. CAMPBELL and HUGH GARLAND}

From the Departments of Neurology, Bristol Royal Hospital, and the General Infirmary at Leedis

The object of this paper is to record three examples of a neurological disorder which we think has not been previously observed. The three patients, seen in 1948 and 1954, seem to have been clinically identical and in the two who died there are striking similarities in the histological changes in the spinal cord. The most striking clinical feature in all three was myoclonus, largely limited to the legs. Histological studies suggest that the syndrome resulted from attack by a virus and in the two fatal examples previous $x$-irradiation may have been an aetiological factor.

\section{Case Reports}

Case 1.-A man, aged 30, a parcels vanman, was admitted to Southmead Hospital, Bristol, on August 24, 1954, complaining of general malaise with myoclonic contractions and stiffness of the legs.

He was found to be a diabetic at the age of 25 and since then had been taking 30 to 40 units of zinc protamine insulin (Z.P.I.) daily. There was nothing relevant in his family history. In December, 1953, he was seen by an orthopaedic surgeon because of low back pain. He was treated with a plaster jacket without benefit and in April, 1954, was considered to be suffering from ankylosing spondylitis, although at that time the blood sedimentation rate was normal and radiological changes in the spine were indefinite; at the same time, chest expansion was limited and back movements were stiff. He was referred to a radiotherapist and given between $900 \mathrm{r}$ and $1,100 \mathrm{r}$ in 31 days to the whole of the spine, the higher dose being given in the mid-dorsal region. Treatment was completed on July 1, 1954. The skin received $1,800 \mathrm{r}$ and the upper limit of treatment was about the second cervical vertebra. When last seen by the radiotherapist on August 18, 1954, he still had lumbar pain though it was now radiating down the legs.

On admission to hospital on August 24, 1954, there was constant though very variable contraction of all the muscles of the abdominal wall and the legs. The contractions occurred in attacks which were at the rate of about 20 a minute and each muscle spasm was associated with severe pain and excessive sweating. The temperature had risen to $102^{\circ} \mathrm{F}$. The diabetes had become difficult to control and the dose of Z.P.I. had to be increased to 50 to 60 units daily. During the next few days the muscular contractions spread into the chest muscles and the sternomastoids and the temperature rose to $104^{\circ} \overline{\bar{p}}$. On August 31 the intercostal muscles were so involied that there was difficulty with respiration; when the respiratory rate had risen to 48 the patient became disorientated and confused. Intramuscular sedatives had little effect. Ir was then noticed that the slightest exte:nl stimulus would precipitate muscular contractions amod for this reason detailed examination of the nervors system was limited, though no other abnormality detected. By this time morphia was found to be one.of the most satisfactory drugs in controlling the musce spasms. It was at this stage that he was first seen by one of us (A.M.G.C.), but on that date the respirag gipy rate continued to rise, he became delirious, and glieed before artificial respiration had been attempted.

Histological Examination.-This was performed $\overrightarrow{\mathrm{b} y}$ Dr. R. M. Norman, at the Frenchay Hospital, Berstol, and the following is his report:-

The brain and spinal cord were normal to the ingerd eye.

Blocks of tissue were taken from representative args of the cerebral cortex, basal ganglia, cerebellum, pouss, and medulla. The spinal cord was sampled from cervical, thoracic, and lumbar segments. Celloidin sections w\&్ge stained for nerve cell bodies by carbol azure and myelin by Heidenhain's method. The following methoils were used with frozen sections; Bielschowsky's stain for axis cylinders, Scharlach R. for lipid, Holzar's method for fibrillary astrocytes, and Anderson's modification of the Kultschutzy-Pal stain for myelin. Paraffin sectiø̄s were stained by haematoxylin and eosin.

Spinal Cord.-Perivenous cuffing by lymphocytes seen at all levels (Fig. 1), its intensity varying from section to section but the inflammatory cells rarefy exceeded a depth of two or three rows. Cuffing was most conspicuous in the zone of white matter adjacent to the cornua, the vessels often being dilated but $\mathrm{mot}$ showing extravasation of red cells or oedema fluid. The leptomeninges of the anterior fissure contained a lymphocytes.

Microglial cells in the white matter generally exhibied a faint staining of their processes in the carbol azose (Nissl) preparations, but no hypertrophic furms were present. Localized aggregations of microgliocytes we seen either in relation to small blood vessels or cas isolated glial stars and seldom exceeded six per section (Fig. 3). In the anterior horns microglial nuclei wise 


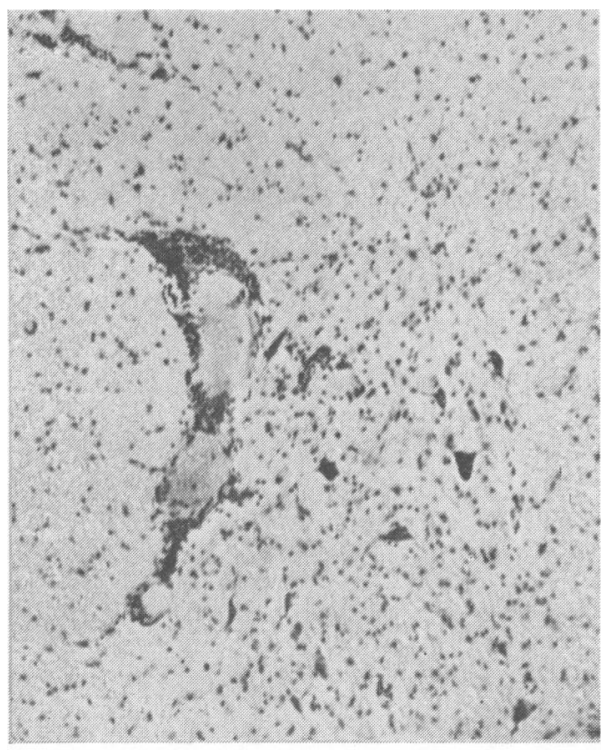

FIG. 1

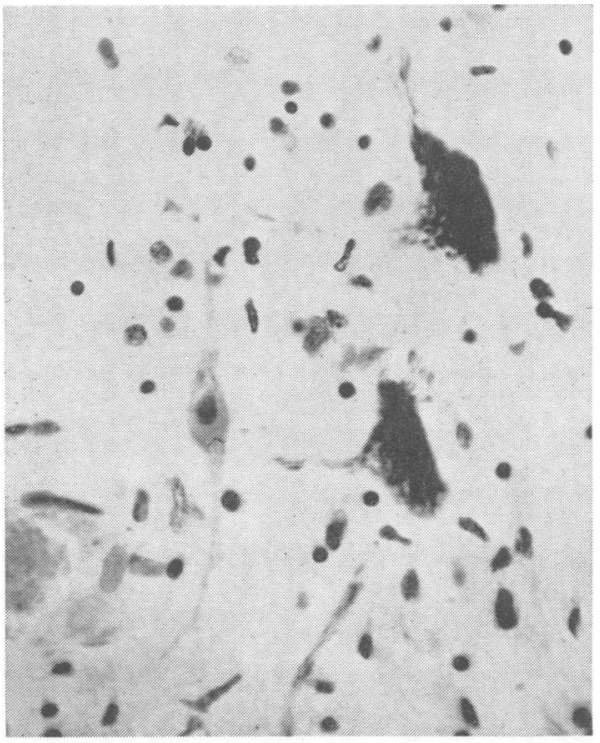

FIG. 2

FIG. 1.-Case 1: Spinal cord, a mid-thoracic segment. Lymphocytic cuffing of vessels. Carbol azure stain, low power.

Fig. 2.-Case 1: Shrunken, chromatolytic nerve cell in the anterior horn of a cervical segment. Carbol azure stain, high power.

FIG. 3.-Case 1: A microglial nodule in the white matter of the spinal cord. Carbol azure stain, high power.

FIG. 4.-Case 1: Cervical spinal cord. A figure of neuronophagia in the anterior horn.

FIG. 5.-Case 1: A microglial star in the lateral cuneate nucleus.

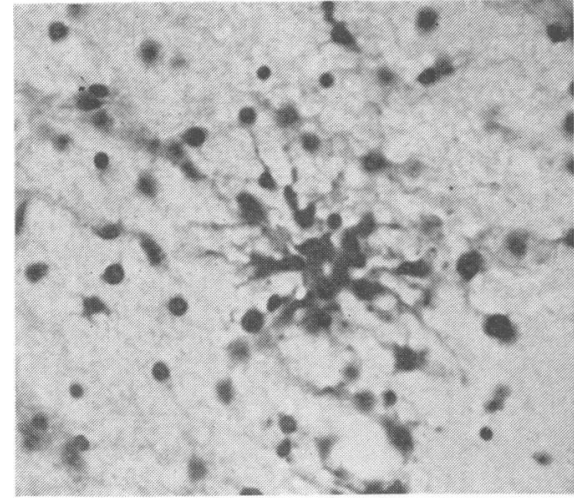

FIG. 3

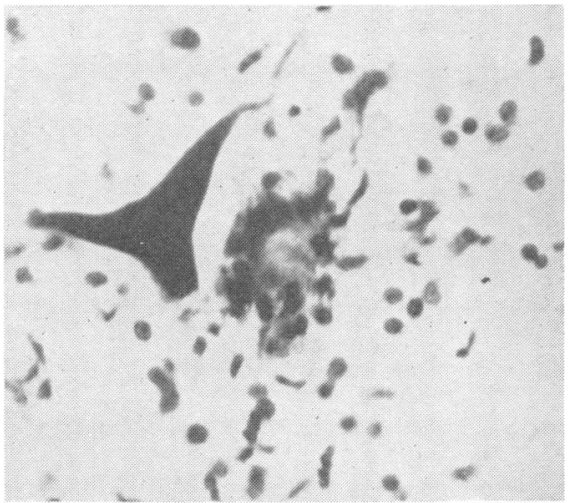

FIG. 4

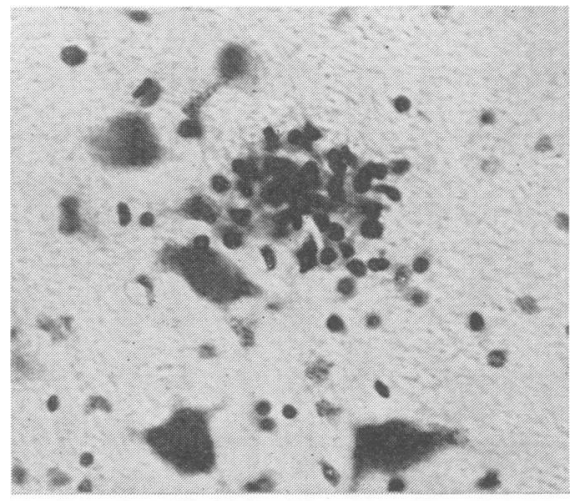

FIG. 5 
sometimes grouped around poorly staining nerve cells and a few denser nodular formations resembling figures of neuronophagia were occasionally found (Fig. 4). Especially in the cervical cord a more diffuse proliferation of microglia could sometimes be demonstrated and this gave a patchy, increased cellularity to the grey matter.

The majority of the nerve cells had normal nuclei and Nissl substance, though the cytoplasm of many stained darkly with carbol azure. Some shrunken, deeply stained anterior horn cells with wavy processes were present at all levels of the cord and a few faintly staining small neurons were also seen. In the latter cells the Nissl bodies had disappeared, the cytoplasm staining a uniform pale blue colour with carbol azure or pink with eosin (Fig. 2). The nuclei usually stained poorly and in some instances showed merely as a few fine chromatin particles. Only a few of these degenerate cells showed satellitosis by microglial cells.

Brain.-A small number of microglial nodules were seen in the medulla (Fig. 5), and also in the central white matter of the cerebellum. There was a sparse and patchy lymphocytic infiltration of the cerebellar leptomeninges. Cuffing of the vessels was only seen in one situation above the level of the spinal cord, namely, in the internal capsule. Some of the nerve cells in the substantia nigra had shrunk markedly but no free pigment or glial activity was present. Here and there, in the centrum semiovale and cores of gyri, perivascular spaces had become widely dilated. The conspicuous lacunae so formed were filled with a delicate glio-mesodermal meshwork which contained small groups of compound granular corpuscles and showed a mild gliosis at their margins.

Elsewhere in the brain no significant pathological changes were found in the numerous areas examined.

In this case the lymphocytic cuffing and microglial nodules, which are features common to many types of virus infections of the nervous system, were almost exclusively found in the spinal cord. The absence of polymorphonuclear infiltration and the inconspicuous damage to the anterior horn cells distinguishes the condition from poliomyelitis. It is more difficult to rule out encephalitis lethargica as the pathogenetic agent, though there were no inflammatory lesions in the sites of predilection of this disease, namely the substantia nigra, periaqueductal grey matter, hypothalamus, or the region of the third ventricle. It is, however, well known that the spinal cord may rarely be substantially implicated in this condition. There are also great variations in the severity of the pathological process in encephalitis lethargica, and in those dying about a week after the onset of the illness there has been a discrepancy similar to that seen in the present case between the severity of the neurological illness and the paucity of the demonstrable neuronal damage.

Two other pathological findings in this case require comment. The abnormally dense gliosis found in the white matter of the spinal cord clearl antedated the terminal illness and is probably to bo regarded as a sequel to the radiotherapy of the spines Damage to the astrocytes is a prominent feature the lesions produced by irradiation of experimentab animals and it is reasonable to suppose that mildêf dosage could induce proliferative changes. The dilatation and fibrosis of the perivascular spacs seen here and there in the white matter of the hemispheres are also evidently unrelated to the encephal tic process.

The most striking features of this case were the sudden onset of a febrile illness associated wit widespread mycolonus, severe pain, and drenchin sweats. At all stages the legs were most severe involved, though there was terminal spread to the respiratory and sternomastoid muscles. The nature of the histological changes would make it fairiy certain that the main aetiological factor was a virugs infection.

Case 2.-A man, aged 35, a railway shunter, was admitted to Ham Green Hospital, near Bristol, on July 4 1954. He was very ill with profuse sweating and involuntary spasms of the abdominal muscles occurring every few minutes.

The only feature of the previous history that might relevant was that he suffered from canicola fever fith lymphocytic meningitis (serological proof) in 1949; कhis was followed by no sequelae. On July 3, 1954, he gin plained of a sore throat and the following day had viodem involuntary spasms of the abdominal muscles, $8 \mathrm{a}$ ticularly the recti, which the patient likened to serere hiccoughs. Apart from these spasms, which occufred with great regularity every few minutes, neurologic examination appeared to be negative. The spasms were painful though the pain disappeared as the muscles relaxed; they occurred both day and night and preventeq sleep. They continued during the next few days and disappeared towards the evening of July 6 . During th period the temperature was 101 to $103^{\circ} \mathrm{F}$., the puls rate 105 , and the respiration rate 24 . The cerebrospina fluid on July 4 was normal in all respects, The bloof picture showed a leucocytosis of 16,900 (polymorph cells $87 \%$ ) on July 5 , though the count had fallen to normal on July 7. Blood culture was sterile and paire samples of blood for virus investigations produced negative results. The patient made a rapid recover and apart from slight giddiness on getting up on July he had no further symptoms. He was last seen of April 25, 1955, when he was normal and working.

This patient resembles Case 1 in some respects. The myoclonic jerks were limited to the abdominat muscles, each phase of myoclonus was of shorter duration, and the intervals between these phases much longer; otherwise there was a strong similarit in the appearance of the muscle spasms. Again the myoclonus was associated with severe sweating and with pyrexia. This patient had not been subjecteg 
to radiotherapy but had had a previous meningeal illness which may or may not be relevant.

Case 3.-A man, aged 32, was admitted to the General Infirmary at Leeds on December 15, 1947, with a threemonth history of swelling of the face and neck resulting from mediastinal compression. Radiographs of the chest showed several large masses on either side of the mediastinum and independent of the aorta; it was thought that the pathology was either Hodgkin's disease or lymphosarcoma. The Wassermann reaction was negative. The patient was given a course of deep $x$-ray therapy to the dorsal region on eight days between January 2 and January 16, 1948; the rays were applied over the lumbar and thoracic regions only. The symptoms improved markedly and he was discharged on January 16; subsequently the radiological shadows disappeared entirely.

On April 18, 1948, he began to notice stiffness of the legs which rapidly became worse so that he was unable to walk on April 22, and by this time he had noticed frequent involuntary twitching of the leg muscles. He was readmitted to the General Infirmary at Leeds on April 28, and by this time had extremely severe and painful spasms of the legs, accompanied by drenching sweats. Any type of stimulus to the legs evoked a painful spasm, so that detailed examination was impossible. The temperature had already risen to $105^{\circ} \mathrm{F}$., though this was lowered by tepid sponging. The twitching was so frequent and so distressing that he was given a spinal anaesthetic under pentothal anaesthesia; cerebrospinal fluid removed at that time was normal in all respects. The spinal anaesthetic gave complete relief from muscle spasms for about 24 hours, after which they recurred but were again relieved by a spinal anaesthetic. A number of drugs were tried in an effort to control the spasms, including morphia, pentothal, pethidine, and avertin, but relief was negligible and finally curare was given; in the first instance $60 \mathrm{mg}$. in an aqueous solution was given over a period of four hours. This produced relief from the spasm and later $30 \mathrm{mg}$. was given three hourly, with considerable relief. By May 14 a reasonable control had been established by the use of $50 \mathrm{mg}$. curare in oil together with $10 \mathrm{mg}$. in an aqueous solution, each given at three-hourly intervals. About this time a little twitching had appeared in the sternomastoid muscles as well as in the abdominal and spinal muscles and it became necessary to increase the dose of curare. At this stage it became essential to use an artificial respirator, and the patient died on May 24, 1948. Over the period of 16 days this patient was given $3,065 \mathrm{mg}$. of curare $(2,625$ in oil and 440 in aqueous solution). Towards the end of the illness, although physical examination remained impossible, it was thought that he had developed a lower motor neuron type of weakness in the legs.

Histological Examination.-This was done by Dr. J. G. Greenfield at the National Hospital, Queen Square, London. He reports as follows:-

No macroscopic abnormality was seen in the brain or spinal cord.

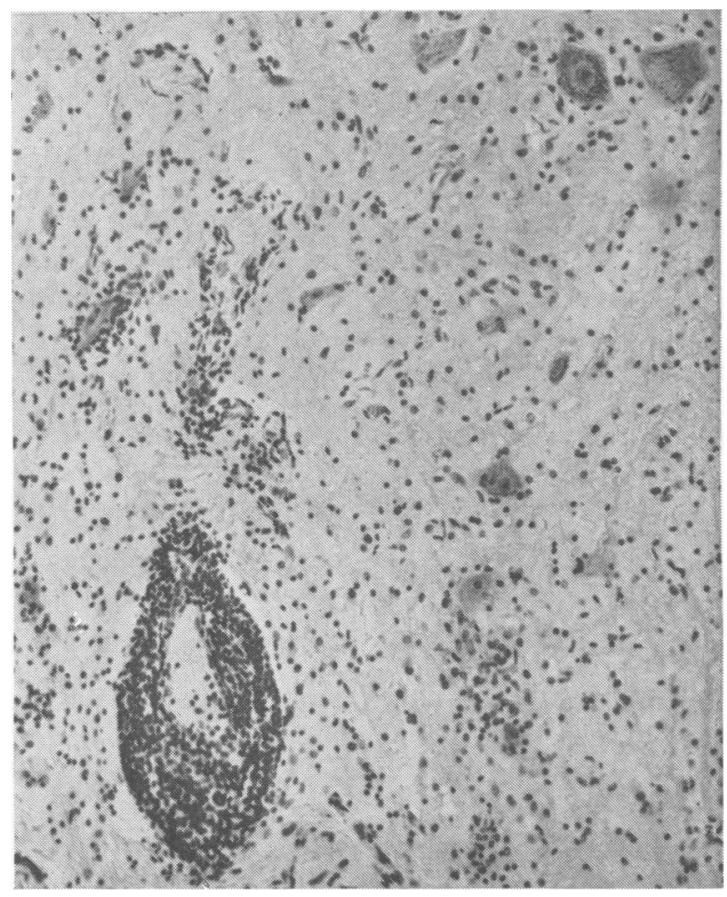

Fig. 6.-Case 3: L.4. There is lymphocytic cuffing of a vessel and several anterior horn cells are undergoing neuronophagia. (Haematoxylin and eosin.)

Sections were made of motor cortex and basal ganglia in the coronal plane through the posterior half of the putamen and globus pallidus and thalamus, including the convoluted area of the hippocampus. These and sections through the mid-brain and cerebellum showed no abnormality.

In the medulla the only abnormality was in an area in the descending trigeminal nucleus where there were two vessels cuffed with lymphocytes and small foci of microglial overgrowth rather larger and more diffuse than glial stars. The cervical cord was normal.

In the third, fourth, and fifth thoracic segments there were several nerve cells in both ventral and dorsal horns which showed degeneration with rings of microglial cells round them, as well as cuffed vessels in the grey matter. Lesions of this kind of slight but variable intensity were seen in the lower thoracic segments, but in the lumbar and sacral segments reached their greatest intensity (Fig. 6). They affected the dorsal horns down to their cap of grey matter, which at some levels was very heavily infiltrated in a focal manner. There were also heavily infiltrated vessels running out through the white columns, but these were otherwise quite normal. The nerve cells, which were ringed by phagocytes, had a darkly staining nucleus and usually had lost their more central Nissl granules (Fig. 7), but many retained a layer of these under the surface of the cell. No inclusion bodies were seen in them with ordinary staining methods. Certainly a larger proportion of neurons in the dorsal than in the ventral horns were degenerated and Clarke's column did 


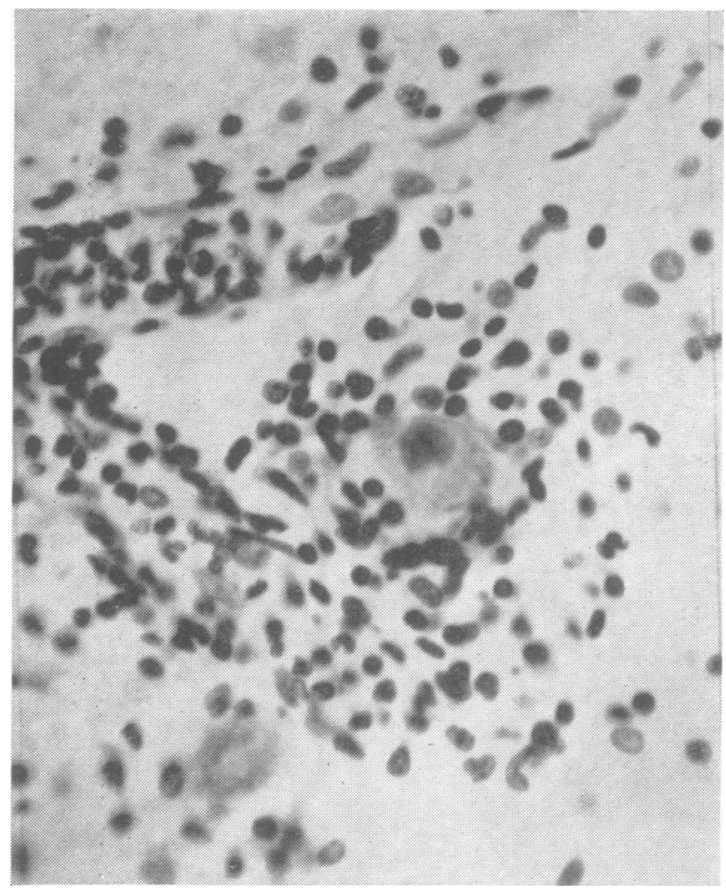

Fig. 7.-Case 3: L.3. High power view of a nerve cell in the anterior horn surrounded by inflammatory cells and showing diffuse chromatolysis and early nuclear damage. (Haematoxylin and eosin.)

not escape. Some cells showed rings of cells round them but little change, others were degenerated but had no excess of cells in their vicinity. Perivascular infiltration was here intense. No vascular changes were seen except in a few intramedullary arterioles at L.5 and S.1 where the media was thickened and rather hyaline.

There was no doubt that some clumps of microglial cells overlay the remains of nerve cells both in the ventral and dorsal horns. The appearance in that respect (in the ventral horns) resembled poliomyelitis.

The appearances seemed to be altogether in favour of the diagnosis of " subacute encephalomyelitis", i.e., an infection, presumably of virus nature, involving the grey matter both ventral, dorsal, and central of the cord and medulla. The virus of poliomyelitis did not seem to be implicated as the dorsal horns were so much more affected and clinically there appeared to have been little resemblance.

There seems little doubt that the clinical syndrome in this patient was the same as that in the two previous examples and equally little doubt about the histological identity of Cases 1 and 3. The presumed malignant masses seen radiologically in December, 1947 , had left no trace at the necropsy, though it would seem a reasonable assumption that, whatever their precise nature, they would recur. It is doubtful whether anytning more could have been done for this patient at the time, though it seems highy probable that with methods of artificial respirat 8 n available in 1956 his life could have been savedgas far as the neurological syndrome was concerned. The increased neuronal damage seen in Case 3 ço be explained on the longer duration of the illness, six weeks compared with one week.

\section{Discussion}

The clinical similarity of these three cases $\underset{\mathrm{F}^{i}}{\mathrm{i}}$ undoubted; all showed involuntary myoclonic movements beginning in the legs and trunk, and gn all there was a high fever with severe sweating. T⿰亻 pathological picture confirmed that in two damage was most extensive in, indeed largêty limited to, the spinal cord. The myoclonic movements appear therefore to have originated in the spinal cord itself and the pathogenic agent cơncerned appears to have produced an excitatoy reaction rather than a paralytic one. Recent ofscussion on myoclonus and its origin has shown that no pathology is peculiar to the condition, and it can be associated with cortical, cerebellar, apd brain-stem lesions; in our cases the myoclonus drias almost certainly determined by the spinal बoㅏ disease.

Friedreich (1881) described paramyoclonus n⿳⺈冂䒑十⺝丶tiplex, which consisted of myoclonic contractions of the trunk and extremities rarely involving the fage. The contractions were short and lightning-like bigt involved a large number of muscles without moring the limb, the twitching being separated by vafious time intervals. Bradshaw (1954) defined myoclontss as " a disturbance of neuronal activity characterized by very sudden, involuntary jerks which fope arhythmic and asynergic involving portions of muscles, whole muscles or muscle groups". ㄱe suggested that during relaxation an excitatory sta is set up by neurons concerned with muscle streng?h and that this appears to be at spinal level in certain cases since there is no involvement of the crantal nerves and no cortical " march ". He suggested that, as in our cases, physiological afferent impulses produce a sufficient stimulus to provoke involuntary jerks. He also suggested that intercalated neurows within the dorsal horn are primarily affected agid that the anterior horn cells are only affected secondarily. It appears that the neuronal activity in oir patients arose in this way from the spinal cord.

Van Bogaert, Radermecker, and Titeca (1950) have reviewed the causes of myoclonus and mention the infective-encephalitic group. They emphasize that myoclonus has been recorded particularly in subacute inclusion encephalitis in children afd occasionally in encephalitis associated with specific fevers such as whooping cough. In particu估 
myoclonus was occasionally a characteristic of encephalitis lethargica. Von Economo (1931) in his monograph describes a hyperkinetic poliomyelitic form of encephalitis lethargica associated with extensive brain-stem damage, and discusses the very severe myoclonic contractions which occur in this type of the disease. Many of the victims began with rigidity of the legs followed by myoclonic jerks of leg and abdominal muscles and, as in our cases, the abdominal pain was so severe from contraction of the recti that some surgical abdominal catastrophe was considered in the differential diagnosis.

Sicard (1920) was one of the first to emphasize myoclonic encephalitis lethargica and Walshe (1920), quoting one of Sicard's cases, said that the myoclonus was followed by lower motor neuron peripheral paralysis of the arm after the contractions had ceased, probably indicating that the anterior horn cell was the common factor in both the myoclonic contractions and the subsequent paralysis.

That certain examples of encephalitis lethargica showed spinal cord damage there is no doubt, but whether it resembles in any way the damage shown in our patients is difficult to say. Many viruses can attack the nervous system and it is impossible to be certain without an epidemic that sporadic cases really fall into this group. Cases resembling encephalitis lethargica may still occur sporadically.

The other interesting point about two of these patients was their exposure to radiotherapy. It seems more than a coincidence that two out of three examples should have had radiotherapy to the spine less than six weeks before the onset of their neurological illness. The third patient had a neurological illness taking the form of meningitis, and possibly encephalitis, four years before. Perhaps the $x$ rays and the canicola fever acted upon the nervous system in such a way as to predispose to later infection with a virus by lowering the resistance to that virus or by altering the immunity reaction of the nervous system. Clemente and Holst (1954) have shown that there is considerable disturbance of the blood-brain barrier after exposure to $x$-ray treatment and they showed by the passage of trypan blue dye that permeability of this barrier is greatly increased.

This hypothesis receives some support from several observations appearing in the literature, which have suggested a causal relationship between irradiation and subsequent infection. One of the first was made by Lyman, Kupalov, and Scholz (1933) who noted that three out of four irradiated dogs developed a distemper-like encephalitis. In two of these animals the inflammatory changes were widespread and not symptomatically related to areas of radiological exposure.
Pendergrass, Hodes, and Groff (1940) reported three human cases of purulent infection of the brain or its covering following large doses of $x$ rays given for a carcinoma of the scalp, and in the discussion following this paper Dyke referred to several incidents of epidural abscess occurring weeks or months after irradiation for a tumour.

Schaltenbrand (1935) described an illness resembling encephalitis, later followed by epilepsy, in a child whose scalp had been exposed to radiotherapy.

These examples strongly support the theory that the resistance of the nervous system to either pyogenic or virus infection may become impaired as a result of previous irradiation. The wide acceptance of the statement that the central nervous system is relatively insensitive to $x$ rays has encouraged excessive dosage and a disregard for its dangers in human patients. Pennybacker and Russell (1948) have already shown that massive focal necrosis and gliosis follow irradiation of the brain after a latent period of five to nine years. This latent period is difficult to explain but they suggest that the damage is probably secondary to fibrinoid necrosis, fibrosis, and vascular damage, and is a very slowly progressive process gradually producing the later clinical effects. They also suggest that vascular permeability may be a factor. The examples they dealt with were entirely brain lesions, but Stevenson and Eckhardt (1945) have described necrosis in the spinal cord and have emphasized the dangers that may occur with irradiation of the spine.

It does not seem to us likely that the generalized increase in neuroglia in the spinal cord in our first case was the consequence of irradiation, as might possibly be suggested. It is striking in our two cases exposed to irradiation that there was the same latent interval between the exposure and the development of symptoms. This would suggest that the $x$ rays produced a slowly progressive damage lowering the resistance to an infective process some time after the cessation of exposure.

\section{Summary}

Three patients are described who appear to have been suffering from an identical syndrome; further weight is lent to its identity by the similarity of histological changes in two fatal examples.

The illness pursued a subacute and probably always reversible course characterized by violent myoclonus largely confined to the legs.

The histological changes are those of an inflammatory lesion confined to the grey matter of the cord, particularly in the dorsal and lumbar regions.

$X$-irradiation of the spine may have played an aetiological role. 
We are grateful to Dr. James Macrae for referring Case 2 to one of us (A.M.G.C.) and to Professor T. F. Hewer and Dr. H. Urich for reference of post-mortem material in Case 1.

\section{REFERENCES}

Bogaert, L. van, Radermecker, J., and Titeca, J. (1950). Folia psychiat. (Amst.), 53, 650 .

Bradshaw, J. P. P. (1954). Brain, 77, 138.

Clemente, C. D., and Holst, E. A. (1954). A.M.A. Arch. Neurol. Psychiat., 7, 166.
Economo, C. von (1931). Encephalitis Lethargica, trans. Newmaz. K. O. Oxford University Press, London.

Friedreich, N. (1881). Virchows Arch. path. Anat., 86, 421.
Lyman, R. S., Kupalov, P. S., and Scholz, W. (1933). Arch. Neura Lyman, R. S., Kupaov, P. S9, and Scholz, W. (1933). Arch. Neurब. Psychiat (Chicago), 29, 56.
Pendergrass, E. P., Hodes, P. J., and Groff, R. A. (1940). Amer.ఫ్
Roentgenl., 43, 214.

Pennybacker, J., and Russell, D. S. (1948). Journal of Neurology Neurosurgery, and Psychiatry, 11, 183.

Schaltenbrand G. (1935). Nervenartz, 8, 62.

Sicard, J. A. (1920). Bull. Soc. méd. Hp. Paris, 44, 294.

Stevenson, L. D., and Eckhardt, R. E. (1945). Arch. Path. (Chicag 39, 109.

Walshe, F. M. R. (1920). Brain, 43, 197.

\section{THE AUGUST (1956) ISSUE}

The August (1956) issue contains the following papers:-

Diffuse Degeneration of the Cerebral White Matter in Severe Dementia Following Head Injury. Sabina J. Strich

Retinal Degeneration in Hereditary Ataxia. Å. Björk, U. Lindblom, and L. Wadensten.

Paroxysmal Dysphasia and the Problem of Cerebral Dominance. H. Hécaen and Malcolm Piercy.

The Prolonged and Distant Effects of Experimental Brain Injury on Cerebral Blood Vessels as Demonstrated by Radio. active Indicators. James B. Brierley.

Multilocular Encephalomalacia. W. Kramer.

The Pathological Effects of Cerebral Arteriography. T. Crawford.

Electrophoresis of Sera in Multiple Sclerosis and Other Neurological Diseases. Elizabeth M. Press.

Benign Congenital Myopathy with Myasthenic Features. John N. Walton, Norman Geschwind, and J. A. Simpso啳.

A Controlled Clinical Study of Chlorpromazine and Reserpine in Chronic Schizophrenia. Michael Shepherd and Davidd C. Watt.

Book Reviews.

A number of copies are still available and may be obtained from the Publishing Manager, British Medical Association, Tavistock Square, W.C.1, price 12s. $6 d$. 